\title{
TINDAK TUTUR DIREKTIF DALAM SINETRON PREMAN PENSIUN DI RCTI
}

\author{
Vina Shifa Fauzia ${ }^{\varpi}$, Haryadi, dan Septina Sulistyaningrum
}

Jurusan Bahasa dan Sastra Indonesia, Fakultas Bahasa dan Seni, Universitas Negeri Semarang, Indonesia

\begin{tabular}{l}
\hline Info Artikel \\
\hline Sejarah Artikel: \\
Diterima Januari 2019 \\
Disetujui Februari 2019 \\
Dipublikasikan Maret 2019 \\
\hline Keywords: \\
directive act speech; types \\
of directive speech acts; \\
function of directive speech \\
acts; Preman Pensiun soap \\
opera
\end{tabular}

opera

\begin{abstract}
Abstrak
Penelitian ini bertujuan untuk mendeskripsikan jenis, fungsi, dan efek tindak tutur direktif dalam sinetron Preman Pensiun di RCTI. Pendekatan penelitian yang digunakan dalam penelitian ini adalah pendekatan teoretis dan metodologis. Pendekatan teoretis yang digunakan adalah pendekatan pragmatik, sedangkan pendekatan metodologis yang digunakan adalah pendekatan deskriptif dan kualitatif. Data dalam penelitian ini berupa penggalan tuturan para tokoh sinetron Preman Pensiun, sedangkan sumber data penelitian ini adalah tuturan sinetron Preman Pensiun. Pengumpulan data dilakukan dengan metode simak dengan teknik dasar yaitu teknik sadap, dilanjutkan dengan teknik lanjutan yaitu teknik simak bebas libat cakap yang kemudian diikuti dengan teknik rekam dan teknik catat. Analisis data menggunakan metode heuristik. Penyajian hasil analisis data menggunakan metode informal. Hasil penelitian dalam sinetron Preman Pensiun di RCTI ditemukan berbagai variasi tuturan. Berdasarkan jenis tindak tutur yang ditemukan adalah tindak tutur langsung, tindak tutur tidak langsung, tindak tutur harfiah dan tindak tutur tidak harfiah. Berdasarkan fungsi tindak tutur direktif yang ditemukan adalah tindak tutur direktif fungsi menyuruh, meminta, menyarankan, memaksa, mengajak, dan menantang. Berdasarkan efek yang muncul adalah efek positif dan efek negatif. Efek positif meliputi membuat senang, membuat lega, mendorong, dan membuat tertarik. Efek negatif yang muncul adalah membuat takut, membuat marah, dan membuat sedih.
\end{abstract}

\begin{abstract}
This study aims to describe the type, function, and effect of directive speech acts in Preman Pensiun soap opera in RCTI. The research approaches used in this research are theoretical and methodological approach. The theoretical approach used is pragmatic approach, while the methodological approaches used are descriptive and qualitative approach. Data is in the form of speech fragments of Preman Pensiun soap opera figures, while the data source of this research is the speech of Preman Pensiun soap opera. Data collection was done by observation method with basic technique that is tapping technique, followed by advanced technique that is involved conversation observation technique then followed by Presentation of data analysis result uses informal method. Results of research of Preman Pensiun soap opera in RCTI found various variations of speech. Based on the types of speech acts are direct speech acts, indirect speech acts, literal speech acts and non-literal speech acts. Based on the function are the directive speech act with function of telling, asking, suggesting, forcing, inviting, and challenging. Based on the effects that appear are positive effects and negative effects. Positive effects include making fun, making relief, encouraging, and attracting. Negative effects that appear are making fear, making angry, and making sad.
\end{abstract}

(C) 2019 Universitas Negeri Semarang

\footnotetext{
$\triangle$ Alamat korespondensi:

Gedung B1 Lantai 1 FBS Unnes

Kampus Sekaran, Gunungpati, Semarang, 50229

E-mail: vinashifafauzia@gmail.com
}

ISSN 2252-6315 


\section{PENDAHULUAN}

Manusia akan selalu membutuhkan orang lain dalam melakukan aktivitas kehidupan sehari-hari, sehingga mustahil jika manusia dapat hidup seorang diri. Jadi dapat dikatakan bahwa manusia disebut sebagai makhluk sosial karena selalu berinteraksi dalam melakukan aktivitas kehidupan sehari-hari. Saat berinteraksi dengan sesamanya, manusia memerlukan sebuah alat komunikasi. Alat komunikasi manusia yang digunakan saat berinteraksi dengan sesamanya itu disebut bahasa.

Saat berkomunikasi, manusia menggunakan tuturan-tuturan untuk mengutarakan apa yang ingin disampaikan. Tuturan disebut juga ujaran, yang merupakan sebuah tindakan. Mengujarkan tuturan tertentu dapat dipandang sebagai melakukan tindakan (mempengaruhi, menyuruh), di samping memang mengucapkan atau mengujarkan tuturan itu. Kegiatan melakukan tindakan mengujarkan tuturan itulah yang merupakan tindak tutur atau tindak ujar (Rustono 1999:31). Yule (2006:81-82) mengatakan bahwa dalam usaha untuk mengungkapkan diri mereka, orang-orang tidak hanya menghasilkan tuturan yang mengandung kata-kata dan strukturstruktur gramatikal saja, tetapi mereka juga memperlihatkan tindakan-tindakan melalui tuturan itu, tindakan-tindakan yang ditampilkan lewat tuturan biasanya disebut tindak tutur.

Saat melakukan tuturan, kita membentuk tuturan dengan beberapa fungsi di dalam pikiran. Dalam kegiatan berkomunikasi, setiap penutur hendak menyampaikan fungsi dan maksud tertentu kepada mitra tutur, baik yang tersurat maupun yang tersirat. Oleh karena itu komunikasi yang terjadi harus berlangsung secara efektif dan efisien sehingga mitra tutur dapat memahami fungsi dan maksud tuturan tersebut, agar apa yang disampaikan dapat tersampaikan dengan baik. Rustono (2000:92) menyatakan bahwa fungsi pragmatis adalah fungsi yang diacu oleh maksud tuturan di dalam pemakaiannya untuk berkomunikasi antar penutur. Jadi dapat disimpulkan bahwa setiap tuturan pasti memiliki fungsi dan maksud tertentu, serta efek atau akibat yang ditimbulkan dari tuturan tersebut. Haryadi (2003:271) mengemukakan efek-efek yang ditimbulkan tuturan perlokusi. Berdasarkan dampaknya, tuturan perlokusi dapat diklasifikasikan menjadi dua yaitu efek positif dan efek negatif. Efek positif yaitu efek atau dampak yang baik bagi mitra tuturnya. Efek negatif yaitu efek yang berakibat buruk atau tidak baik bagi mitra tuturnya.
Tindak tutur direktif adalah tindak tutur yang dimaksudkan penuturnya agar mitra tutur melakukan tindakan yang disebutkan di dalam tuturan itu (Rustono 1999:38). Tuturan-tuturan memaksa, mengajak, meminta, menyuruh, menagih, mendesak, memohon, menyarankan, memerintah, memberikan aba-aba, menantang dan sebagainya, termasuk ke dalam jenis tindak tutur direktif ini.

Tindak tutur dan peristiwa tutur selain dapat ditemukan dalam komunikasi sehari-hari dengan berinteraksi secara langsung, dapat juga ditemukan dalam sebuah sinetron. Dalam sebuah sinetron terdapat alur cerita yang dikembangkan dalam bentuk dialog antarpemain, sehingga di dalam sinetron dapat dilihat dengan jelas bagaimana seseorang berinteraksi, berkomunikasi, melakukan tindak tutur dan mengungkapkan ekspresi tokoh dan peran yang mereka mainkan. Hal inilah yang membuat sinetron sebagai media yang layak dan menarik untuk dikaji pada kajian tindak tutur. Salah satu sinetron yang menarik untuk dikaji yaitu sinetron Preman Pensiun. Dilihat dari alur ceritanya, banyak tuturan yang mengandung tuturan direktif. Oleh sebab itu, adanya tindak tutur direktif dalam percakapan tersebut yang melatarbelakangi dipilihnya sinetron Preman Pensiun sebagai objek penelitian.

Masalah yang dikaji di dalam penelitian ini adalah jenis tindak tutur direktif, fungsi tindak tutur direktif, dan efek tindak tutur direktif dalam sinetron Preman Pensiun di RCTI. Tujuan dari penelitian ini yaitu untuk mendeskripsikan jenis, fungsi, dan efek tindak tutur direktif dalam sinetron Preman Pensiun di RCTI.

\section{METODE PENELITIAN}

Pendekatan penelitian yang digunakan dalam penelitian ini adalah pendekatan teoretis dan metodologis. Pendekatan teoretis yang digunakan adalah pendekatan pragmatik, sedangkan pendekatan metodologis yang digunakan adalah pendekatan deskriptif dan kualitatif. Data dalam penelitian ini berupa penggalan tuturan para tokoh dalam sinetron Preman Pensiun di RCTI, sedangkan sumber data penelitian ini adalah tuturan para tokoh dalam sinetron Preman Pensiun di RCTI. Pengumpulan data dilakukan dengan metode simak dengan teknik dasar yaitu teknik sadap, dilanjutkan dengan teknik lanjutan yaitu teknik simak bebas libat cakap yang kemudian diikuti dengan teknik rekam dan teknik catat. Analisis data menggunakan metode heuristik. Penyajian 
hasil analisis data menggunakan metode informal.

\section{HASIL DAN PEMBAHASAN}

Deskripsi pembahasan yang akan dikemukakan pada bagian ini meliputi (1) jenis tindak tutur direktif dalam Sinetron Preman Pensiun di RCTI, (2) fungsi tindak tutur direktif dalam Sinetron Preman Pensiun di RCTI, dan (3) efek tindak tutur direktif dalam Sinetron Preman Pensiun di RCTI.

1. Jenis Tindak Tutur Direktif dalam Sinetron Preman Pensiun di RCTI

Berdasarkan penelitian tindak tutur direktif dalam Sinetron Preman Pensiun di RCTI ditemukan jenis tindak tutur yaitu tindak tutur langsung, tindak tutur tidak langsung, tindak tutur harfiah, dan tindak tutur tidak harfiah.

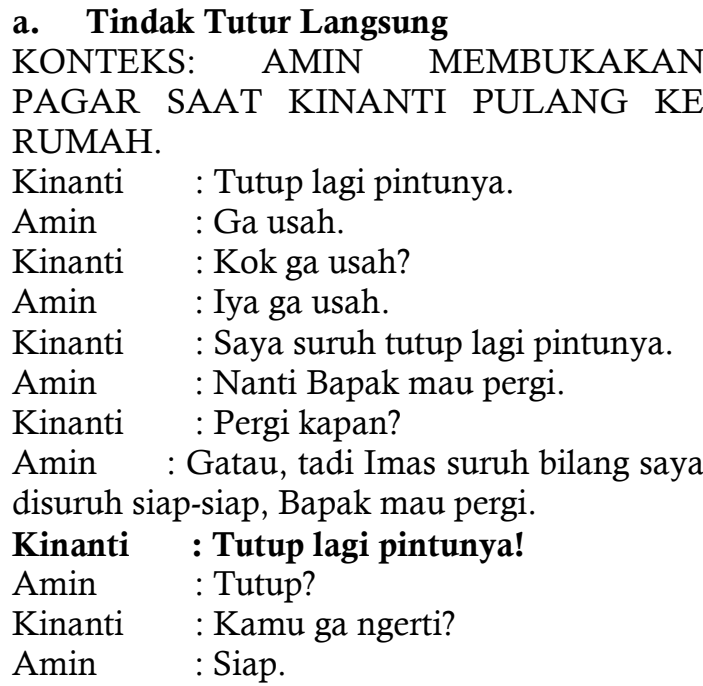

(DATA 1)

Tuturan di atas mengandung jenis tindak tutur direktif langsung. Penanda tuturan ini adalah "Tutup lagi pintunya!" Tuturan ini merupakan tuturan langsung bermodus imperatif karena berfungsi memerintahkan mitra tutur melakukan sesuatu, yaitu Kinanti memerintah supirnya yang bernama Amin untuk menutup kembali pagar rumahnya. Keimperatifan dapat dilihat dari intonasinya. Tuturan tersebut dituturkan dengan intonasi naik di akhir tuturan.

b. Tindak Tutur Tidak Langsung

KONTEKS : KANG BAHAR DAN AMIN SEDANG BERBINCANG DI RUANG TAMU.

Kang Bahar : Saya sudah pensiun dari bisnis saya, dari pekerjaan saya, sudah mungkin jarang untuk bepergian. Saya hanya akan duduk menunggu anak dan cucu saya datang. Saya belum pecat kamu, tapi kamu sudah boleh cari pekerjaan lain.
Amin : Iya.

(DATA 25)

Tuturan di atas mengandung tindak tutur direktif tidak langsung. Penanda tuturan ini adalah "Saya sudah pensiun dari bisnis saya, dari pekerjaan saya, sudah mungkin jarang untuk bepergian. Saya hanya akan duduk menunggu anak dan cucu saya datang. Saya belum pecat kamu, tapi kamu sudah boleh cari pekerjaan lain." Tuturan tersebut merupakan tuturan tidak langsung bermodus deklaratif yang tidak berfungsi untuk menyatakan sesuatu atau memberitahukan suatu informasi, tetapi untuk menyuruh, yaitu Kang Bahar menyuruh Amin untuk mengundurkan diri dan mencari pekerjaan baru. Tuturan deklaratif tampak pada intonasi akhir yang datar dan tidak adanya kata tanya atau perintah.

c. Tindak Tutur Harfiah

KONTEKS : IMAS DAN AMIN BERADA DI DAPUR.

Amin : Imas.

Imas : Apa?

Amin : Jangan judes dong.

Imas : Engga, biasa aja.

Amin : Kalau saya panggil, apa

salahnya jawab pake senyum?

Imas : Langsung aja atuh, ada apa?

Amin : Kopi dong.

Imas : Kalau kamu kebanyakan

minum kopi nanti kamu tambah item.

Amin : Kamu jangan menghina, ini itemnya item luwak, biar item manis rasanya.

Imas : Imas bikinin kopi susu ya.

Amin : : Boleh.

Imas : Biar ga terlalu item.

(DATA 7)

Tuturan di atas mengandung tindak tutur harfiah. Tuturan "Kopi dong" merupakan tindak tutur harfiah karena mempunyai kesamaan antara maksud dan makna tuturan, yaitu penutur meminta kopi kepada mitra tutur. Kata "kopi" dalam tuturan tersebut mempunyai arti yang sebenarnya yaitu minuman yang bahannya serbuk kopi, yang berarti penutur meminta dibuatkan minuman kopi kepada mitra tutur.

\section{d. Tindak Tutur Tidak Harfiah}

KONTEKS : KANG BAHAR DAN KANG MUS SEDANG BERBINCANG DI TERAS RUMAH.

Kang Bahar : Jadi sekarang gimana? Pedagang kaki lima masih susah ditagih sekarang?

Kang Mus : Setelah Akang turun sekarang lancar.

Kang Bahar : Oh itu artinya saya harus turun lagi gitu? 
Kang Mus : Jangan Kang, harusnya itu bisa selesai ditangan saya.

Kang Bahar : Iya! Memang harusnya begitu! Selesai ditangan kamu sebagai tangan kanan saya!

Kang Mus : Iya Kang.

(DATA 13)

Tindak tutur di atas mengandung tindak tutur tidak harfiah. Penanda tuturan ini adalah "Iya! Memang harusnya begitu! Selesai ditangan kamu sebagai tangan kanan saya!" Tuturan tersebut mengandung tindak tutur tidak harfiah karena maksud tuturan tersebut tidak sama dengan makna kata-kata yang menyusunnya. Maksud tuturan tersebut adalah Kang Mus harus menyelesaikan pekerjaan yang sudah diberikan oleh Kang Bahar karena Kang Mus telah dianggap sebagai kepercayaan Kang Bahar. Kata "tangan kanan" dalam tuturan tersebut mempunyai arti kepercayaan, bukan tangan sebelah kanan.

2. Fungsi Tindak Tutur Direktif dalam Sinetron Preman Pensiun di RCTI

Fungsi pragmatis tindak tutur direktif adalah fungsi yang diacu oleh maksud tuturan di dalam pemakaiannya agar mitra tutur melakukan tindakan yang disebutkan di dalam tuturannya. Berdasarkan hasil analisis penelitian ini, fungsi tindak tutur direktif dalam Sinetron Preman Pensiun di RCTI meliputi fungsi menyuruh, fungsi meminta, fungsi menyarankan, fungsi memaksa, fungsi mengajak, dan fungsi menantang.

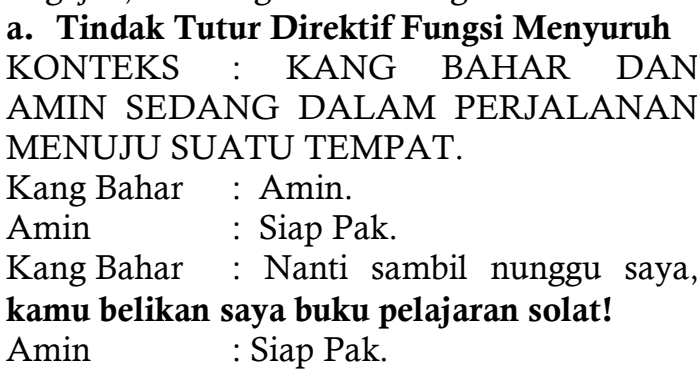

(DATA 2)

Tuturan Kang Bahar mengandung tuturan direktif fungsi menyuruh. Penanda tuturan ini adalah "Kamu belikan saya buku pelajaran solat!" Tuturan tersebut merupakan tuturan direktif menyuruh karena berisi suruhan yang difungsikan untuk menyuruh, yaitu Kang Bahar menyuruh Amin membelikan buku pelajaran solat. Tuturan tersebut memiliki maksud agar Amin melakukan apa yang disebut oleh Kang Bahar, yaitu agar Amin membelikan buku pelajaran solat.

\section{b. Tindak Tutur Direktif Fungsi Meminta}

KONTEKS : KANG MUS DAN

ANAKNYA JANJIAN BERTEMU DI DEPAN STADION PERSIB.

Kang Mus : Kamu kok lama?

Neng : Neng kan pake angkot, makanya beliin motor.

Kang Mus : Kamu masih 14 tahun ga boleh bawa motor.

Neng : Temen Neng 14 tahun juga udah dibeliin motor.

Kang Mus : Ga usah beli motor, nih beli cilok aja (sambil memberikan uang).

(DATA 17)

Tuturan di atas mengandung tindak tutur direktif fungsi meminta. Penanda tuturan ini adalah "Makanya beliin motor." Tuturan yang diujarkan oleh anaknya Kang Mus memiliki maksud agar bapaknya mau menuruti atau memberikan apa yang dikatakannya, yaitu mau membelikan motor. Berdasarkan uraian tersebut maka tuturan yang diujarkan oleh anaknya Kang Mus dapat diklasifikasikan dalam fungsi direktif meminta, yaitu anaknya meminta motor kepada bapaknya yaitu Kang Mus.

$\begin{array}{lcr}\text { c. Tindak Tutur } & \text { Direktif } & \text { Fungsi } \\ \text { Menyarankan } & & \\ \text { KONTEKS : } & \text { KANG } & \text { MUS } \\ \text { MENGUMPULKAN } & \text { SEMUA } & \text { ANAK } \\ \text { BUAHNYA DI MARKAS BESAR. } & \end{array}$

Kang Mus : Kalau bukan cari uang di terminal, kamu mau apa?

Sapri : Gatau Kang.

Kang Mus : Ambil waktu seminggu tiga kali kursus sablon, daripada kamu gambar di badan kamu sendiri lebih baik kamu gambar di kaos.

Sapri : Iya Kang.

(DATA 29)

Tuturan Kang Mus kepada Sapri mengandung tuturan direktif menyarankan. Penanda tuturan ini adalah "Ambil waktu seminggu tiga kali kursus sablon, daripada kamu gambar di badan kamu sendiri lebih baik kamu gambar di kaos." Tuturan yang diujarkan Kang Mus merupakan tuturan yang memiliki fungsi menyarankan, yaitu Kang Mus menyarankan Sapri agar Sapri mengambil waktu seminggu tiga kali untuk kursus sablon daripada badan Sapri digambar seperti tato. Berdasarkan uraian tersebut, maka tuturan tersebut dapat diklasifikasikan dalam fungsi direktif menyarankan, yaitu agar Sapri kursus sablon seminggu tiga kali.
d. Tindak Tutur Direktif Fungsi Memaksa
KONTEKS : KOMAR DAN ISTRINYA SEDANG BERTENGKAR DI RUMAH. 
Istri : Bebep mau punya motor matik bukan buat gaya! Kalau Bebep mau pergi-pergian tukang angkot jarang ada yang mau berhenti! Supir angkot gamau rugi! Bebep bayar satu tapi tempat duduknya kepake 2 !

Komar : Iya Bebep.

Istri : Pokoknya kalo Baba belum bisa beliin motor matik, Baba ga usah pulang! Titik! (menutup pintu rumah)

Komar : Bep, Bep, haduh.

(DATA 28)

Tuturan di atas mengandung tindak tutur direktif fungsi memaksa. Penanda tuturan ini adalah "Pokoknya kalo Baba belum bisa beliin motor matik, Baba ga usah pulang! Titik!" Tuturan tersebut diujakan istri Komar untuk memaksa Komar agar segera membelikan motor matik untuknya karena kalau istri Komar bepergian tidak ada angkot yang mau berhenti dan menumpangi dia. Berdasarkan uraian tersebut, maka tuturan tersebut dapat diklasifikasikan dalam fungsi direktif memaksa, yaitu memaksa Komar membelikan motor matik.

\section{e. Tindak Tutur Direktif Fungsi Mengajak KONTEKS : KINASIH MENEMUI PAPIHNYA (KANG BAHAR) DI RUANG TAMU.}

Kinasih : Ke Saung Udjo yuk.

Kang Bahar : Kenapa tiba-tiba kamu ngajak ke Saung Udjo?

Kinasih : Barusan pas lagi nemenin Kiara duduk di depan main angklung, Kinasih jadi inget pas waktu masih seumuran dia dulu, Kinasih belajar angklung di sekolah.

Kang Bahar : Hayu, Papih juga udah lama ga keluar rumah, Papih mau jalan-jalan sama anak-anak Papih sama cucu-cucu Papih.

(DATA 34)

Tuturan Kinasih kepada papihnya di atas mengandung tuturan direktif mengajak. Penanda tuturan ini adalah "Ke Saung Udjo yuk." Tuturan yang diujarkan Kinasih merupakan tuturan yang memiliki fungsi untuk mengajak, yaitu Kinasih mengajak papihnya pergi ke Saung Udjo. Berdasarkan uraian tersebut dapat diklasifikasikan dalam fungsi direktif mengajak, yaitu Kirani mengajak papihnya ke Saung Udjo.

f. Tindak Tutur Direktif Fungsi Menantang KONTEKS : JUPRI KEMBALI LAGI KE PASAR UNTUK BERTUGAS ATAS PERINTAH KANG MUS.

$\begin{array}{ll}\text { Komar } & \text { : Mau apa kamu? } \\ \text { Jupri } & \text { : Disuruh Kang Mus. } \\ \text { Komar } & \text { : Nyari dompet Imas? } \\ \text { Jupri } & \text { : Kang Mus bukan Imas. } \\ \text { Komar } & \text { : Iya saya tau yang nyuruh } \\ \text { Kang Mus, disuruh apa? }\end{array}$

Jupri : Disuruh gabung lagi di sini.

Komar : Kok Kang Mus ga bilang

sama saya?

Jupri : Gatau kang, kalo Akang ga percaya telfon aja Kang Mus.

Komar : Ga usah!

Tuturan di atas mengandung tindak tutur direktif menantang. Penanda tuturan ini adalah "Kalo akang ga percaya telfon aja Kang Mus." Tuturan yang diujarkan oleh Jupri memiliki fungsi menantang, yaitu Jupri menantang Komar menelepon Kang Mus jika Komar tidak percaya kalau Jupri disuruh gabung lagi di pasar oleh Kang Mus, hal itu dilakukan agar Komar percaya kalau Jupri memang disuruh Kang Mus untuk gabung lagi di pasar. Berdasarkan uraian tersebut maka tuturan yang diujarkan oleh Jupri dapat diklasifikasikan dalam fungsi direktif menantang, yaitu menantang Komar menelepon Kang Mus.

3. Efek Tindak Tutur Direktif dalam Sinetron Preman Pensiun di RCTI

Dalam penelitian ini ditemukan efek yang ditimbulkan tindak tutur direktif yang meliputi efek positif dan efek negatif. Efek positif meliputi membuat senang, membuat lega, mendorong, dan membuat tertarik. Efek negatif meliputi membuat takut, membuat marah, dan membuat sedih.

\section{a. Efek Positif}

Efek positif adalah efek atau dampak yang baik bagi mitra tuturnya. Efek positif dalam penelitian ini meliputi membuat senang, membuat lega, mendorong, dan membuat tertarik.

\section{1) Membuat Senang}

KONTEKS : PRITA MENEMUI JODI SAAT JODI SEDANG BERTUGAS.

Prita : Aku boleh berterimakasih engga? Buat dompet sama hp aku yang udah kembali.

Jodi : Kan kemarin udah bilang terima kasih.

Prita : Maksudnya aku mau ngajak makan siang.

Jodi : Waduh gimana ya saya harus tetep stand by di sini?

Prita : Gimana nanti pulang kerja?

Jodi : Makan siangnya nanti pulang

kerja?

Prita : Bukan makan siang, gatau nanti namanya apa, pokoknya makan.

Jodi $\quad$ : Ya udah terserah Prita aja.

(DATA 48) 
Tuturan "Aku mau ngajak makan siang" menimbulkan efek positif bagi mitra tuturnya. Efek yang dimaksudkan pada tuturan tersebut adalah efek positif menyenangkan atau membuat senang, yaitu tuturan yang diujarkan Prita membuat Jodi merasa senang karena Jodi diajak makan siang oleh Prita.

\section{2) Membuat Lega}

KONTEKS : JONI DAN KOMAR SEDANG BERBINCANG DI MARKAS PASAR. KOMAR KEBINGUNGAN KARENA ISTRINYA MINTA DIBELIKAN MOTOR.

Jodi : Kalau Akang mau beliin motor matik buat istri Akang, bilang aja sama Kang Mus.

Komar : Masa mau beli motor matik aja harus lapor sama Kang Mus.

Jodi : Bukan lapor, Akang kan ga punya uang, bilang.

Komar : Curhat?

Jodi : Bukan curhat, bilang Akang mau beliin motor matik buat istri tapi ga punya uang.

Komar : Iya itu namanya curhat.

Jodi : Bukan.

Komar : Curhat!

Jodi : Saya bingung jelasinnya sama

Akang.

Komar : Gimana kalo saya pinjem uang sama Kang Mus?

Jodi : Itu yang tadi saya maksud.

(DATA 33)

Tuturan di atas menimbulkan efek bagi mitra tuturnya yakni membuat lega. Jodi menyarankan kepada Komar jika Komar mau membelikan istrinya motor matik bilang saja sama Kang Mus untuk meminta pinjaman uang. Tuturan tersebut membuat lega karena saran yang diberikan Jodi kepada Komar membuat Komar lega dan tidak gelisah atau khawatir lagi.

\section{3) Mendorong}

KONTEKS : KANG BAHAR DAN ISTRINYA SEDANG BERBINCANG DI RUANG TAMU

Istri Kang Bahar : Pih, Mamih teh ga sembuh-sembuh.

Kang Bahar

: Mamih harus bertahan, Mamih harus berjuang, Mamih jangan nyerah.

(DATA 10)

Tuturan "Mamih harus bertahan, Mamih harus berjuang, Mamih jangan nyerah" menimbulkan efek positif bagi mitra tuturnya. Efek yang dimaksudkan pada tuturan tersebut adalah efek positif memberi dorongan. Kang Bahar menuturkan bahwa istrinya harus bertahan, harus berjuang, dan jangan pernah menyerah agar segera sembuh dan sehat kembali. Tuturan tersebut memberi motivasi atau dorongan bagi istrinya untuk bisa sembuh dan sehat kembali.

\section{4) Membuat Tertarik}

KONTEKS : KANG MUS DAN CEU EDOH SEDANG BERBINCANG DI RUANG TAMU RUMAH KANG MUS.

Kang Mus : Saya ga bisa ngajak suami Ceu Edoh kerja, tapi kalau Ceu Edoh mau Ceu Edoh bisa kerja di sini bantu-bantu nyuci, masak.

Ceu Edoh : Mau mau mau.

Tuturan "Tapi kalau Ceu Edoh mau Ceu Edoh bisa kerja di sini bantu-bantu nyuci, masak" menimbulkan efek positif bagi mitra tuturnya. Efek yang dimaksudkan pada tuturan tersebut adalah efek positif membuat tertarik. Tawaran Kang Mus untuk bekerja di rumah Kang Mus membuat $\mathrm{Ceu}$ Edoh merasa tertarik untuk bekerja di rumah Kang Mus.

\section{b. Efek Negatif}

Efek negatif adalah efek atau dampak yang berakibat buruk atau tidak baik bagi mitra tutur. Efek negatif dalam penelitian meliputi efek negatif membuat takut, membuat marah dan membuat sedih.

1) Membuat Takut

KONTEKS: SUEB DITODONG OLEH DUA PENODONG DI PINGGIR JALAN.

Penodong 1: Kita ketemu lagi. Mau kemana? Jangan buru-buru!

Penodong 2: Keluarin dompet sama hp! Jangan teriak jangan melawan saya bawa belati, perut kamu bisa keluar!

Sueb : Hp di saku depan, dompet di saku belakang.

Penodong 2 : Terima kasih.

(DATA 27)

Tuturan "Keluarin dompet sama hp! Jangan teriak jangan melawan saya bawa belati, perut kamu bisa keluar!" Menimbulkan efek negatif bagi mitra tuturnya. Efek yang dimaksudkan pada tuturan tersebut adalah efek negatif membuat takut. Tuturan tersebut bermaksud untuk menodong atau meminta dompet dan hp secara paksa dan mengancam akan menusuk perut Sueb menggunakan belati yang mereka bawa. Tuturan tersebut mempunyai efek bagi mitra tutur yakni timbulnya rasa takut karena adanya ancaman akan menusuk perutnya menggunakan belati.

\section{2) Membuat Marah}


KONTEKS : JUPRI KEMBALI LAGI KE PASAR UNTUK BERTUGAS ATAS PERINTAH KANG MUS.

Komar : Mau apa kamu?

Jupri : Disuruh Kang Mus.

Komar : Nyari dompet Imas?

Jupri : : Kang Mus bukan Imas.

Komar : Iya saya tau yang nyuruh Kang Mus, disuruh apa?

Jupri : Disuruh gabung lagi di sini.

Komar : Kok Kang Mus ga bilang sama saya?

Jupri : Gatau kang, kalo Akang ga percaya telfon aja Kang Mus.

Komar : Ga usah!

(DATA 45)

Tuturan tersebut menimbulkan efek negatif bagi mitra tuturnya. Efek yang dimaksudkan pada tuturan tersebut adalah efek negatif membuat marah. Tuturan Jupri kepada Komar membuat Komar merasa jengkel dan marah karena Jupri menantang Komar untuk menelepon Kang Mus.

3) Membuat Sedih

KONTEKS : KANG BAHAR DAN AMIN SEDANG BERBINCANG DI RUANG TAMU.

Kang Bahar : Saya sudah pensiun dari bisnis saya, dari pekerjaan saya, sudah mungkin jarang untuk bepergian. Saya hanya akan duduk menunggu anak dan cucu saya datang. Saya belum pecat kamu, tapi kamu sudah boleh cari pekerjaan lain.

Amin : Iya.

(DATA 25)

Tuturan "Saya sudah pensiun dari bisnis saya, dari pekerjaan saya, sudah mungkin jarang untuk bepergian. Saya hanya akan duduk menunggu anak dan cucu saya datang. Saya belum pecat kamu, tapi kamu sudah boleh cari pekerjaan lain" menimbulkan efek negatif bagi mitra tuturnya. Efek yang dimaksudkan pada tuturan tersebut adalah efek negatif membuat sedih. Tuturan Kang Bahar kepada Amin membuat Amin merasa sedih karena secara tidak langsung Amin akan dipecat dan disuruh mencari pekerjaan baru.

\section{SIMPULAN}

Berdasarkan pembahasan tersebut dapat penulis simpulkan bahwa jenis tindak tutur direktif dalam Sinetron Preman Pensiun di RCTI meliputi tindak tutur langsung, tindak tutur tidak langsung, tindak tutur harfiah dan tindak tutur tidak harfiah. Fungsi tindak tutur direktif dalam Sinetron Preman Pensiun di
RCTI meliputi fungsi direktif menyuruh, fungsi direktif meminta, fungsi direktif menyarankan, fungsi direktif memaksa, fungsi direktif mengajak dan fungsi direktif menantang. Efek yang ditimbulkan tindak tutur komisif dalam Sinetron Preman Pensiun di RCTI meliputi efek positif dan efek negatif. Efek positif meliputi membuat senang, membuat lega, mendorong, dan membuat tertarik, sedangkan efek negatifnya adalah membuat takut, membuat marah, dan membuat sedih.

\section{SARAN}

Berdasarkan analisis yang telah dilakukan dan uraian pada bab-bab sebelumya, ada beberapa saran yang diberikan antara lain (1) Penutur dalam bertutur sebaiknya menggunakan tuturan-tuturan yang santun sehingga tuturan direktif dapat disampaikan secara santun. Penutur hendaknya menggunakan tuturan langsung dengan pertimbangan keefektifan dan kekomunikatifan, dan menggunakan tuturan tidak langsung secara halus tanpa ada sindiran dan celaan.

(2) Para pendengar atau mitra tutur diimbau untuk peka terhadap penggunaan bahasa yang disampaikan penutur sehingga tuturan direktif tidak langsung dan tuturan direktif tidak harfiah dapat tersampaikan dengan baik tanpa merasa tersindir dan tercela.

(3) Para peneliti bahasa diharapkan menjadikan penelitian ini sebagai referensi untuk dikembangkan lebih lanjut agar penelitian ini menjadi lebih sempurna dan dapat menambah khasanah ilmu bahasa. Penulis berharap agar ada penelitian mendalam yang bisa membahas mengenai bahasa dari kajian pragmatik, khususnya yang berhubungan dengan tindak tutur direktif.

\section{DAFTAR PUSTAKA}

Haryadi. 2003. Jenis, Efek, dan Fungsi Tuturan Perlokusi Mahasiswa Kuliah Kerja Nayata Universitas Negeri Semarang di Kabupaten Kendal. Tesis. Universitas Negeri Semarang.

Rustono. 1999. Pokok-pokok Pragmatik. Semarang: IKIP Semarang Press.

2000. Implikatur Tuturan Humor. Semarang: IKIP Semarang Press.

Yule, George. 2006. Pragmatik. Yogyakarta: Pustaka Pelajar. 